\title{
Seeding Without Leading: Making Space for Participant Contribution in Design Elicitation Techniques
}

\author{
Ann Light \\ Sheffield Hallam University \\ Sheffield \\ S1 1WB \\ +44 (0)114225 5555 \\ a.light@shu.ac.uk
}

\author{
Pam Briggs \\ Northumbria University \\ Newcastle upon Tyne \\ NE1 8ST \\ +44(0)1912326002 \\ p.briggs@unn.ac.uk
}

\author{
Karen Martin \\ Bartlett School of Graduate Studies \\ University College London \\ London \\ WC1E 6BT \\ +44 (0)20 76792000
}

karen.martin@ucl.ac.uk

\begin{abstract}
As HCI embraces experience design, it will increasingly rely on new elicitation methods that are capable of drawing out the multi-faceted subjectivities of individuals without being overly prescriptive as to the final design or experience outcome. In this panel we wish to describe and discuss subtle elicitation techniques that allow the elicitation of participant ideas and interests with minimum prejudicing by the researcher. We argue that leaving space for meaning to be made by project informants is a valuable approach to understanding both design requirements and use issues. We show work that has come from taking this approach and discuss why we have been concerned to keep a creative space open in our research and how we invite people into it.
\end{abstract}

\section{Categories and Subject Descriptors J.O general}

\section{General Terms}

Design, Experimentation, Human Factors

\section{Keywords}

Person-centred; meaning; design; future; scenario

\section{INTRODUCTION}

As HCI moves beyond a cognitive methodology and begins to embrace a broader context of everyday life and experience, new methods need to be developed which are able to draw out the multi-faceted subjectivities of individuals. Achieving this without influencing or leading participants is difficult however. In this panel we wish to explore how this might be possible and we present three projects that have made their mission the elicitation of participant ideas and interests with minimum prejudicing by the researcher. We argue that leaving space for meaning to be made by project informants is a valuable approach to understanding both design requirements

(C) The Author 2008.

Published by the British Computer Society and use issues. We will show work that has come from taking this

approach and discuss why we have been concerned to keep a creative space open in our research and how we invite people into it. We will show and discuss excerpts from:

- a method derived from performance for engaging people in thinking about digital design decisions;

- a film of a futuristic interaction in which a device is suggested but never shown, thereby encouraging audience speculation.

- a workshop series exploring the transitory social and spatial context of in-between spaces and the implications of this for technology appropriation, use and design.

Each is united by its intent to give permission to participants to bring their own meaning, ideas and interests to the technique, and the way that it is designed with space for this contribution.

\section{THE BACKGROUND}

Elicitation techniques have long sought to avoid 'the leading question' that will prejudice the informants in a study by giving them ideas or words to use in place of their own. Beyond the need for methodological rigour to ensure that findings are as asserted, researchers have looked for new and better ways to generate insights, using both quantitative and qualitative processes that leave space for ideas to appear from those being studied. In this way, social scientists have sought to engage participants on their own terms, even though the topic under review has been determined by the questioner.

One means of so engaging participants is to capture early design ideas in a form that can demonstrate a problem space without being unduly focused upon the technologies involved. Scenarios can do this by focusing upon the activities rather than the technologies that underpin interaction (eg [1]). Scenarios, then, communicate the essence of an interaction without specifying its form in any explicit detail. However we should note that, for many designers, this allusory nature of scenarios can be problematic. Using a more extreme technique, it is possible to eliminate the scenario and use other tools to elicit key concepts from potential users, leading to a purely person-centric view of particular phenomena (eg [2] on nondirective qualitative interviewing, or [3] on randomizing contexts).

In the HCI2006 workshop on "Designing the Not Quite Yet" [4], 'scenarios' were juxtaposed with 'seeds'. Scenarios by their nature offer those that work with them a story to accept or 
reject, develop or critique and this will determine the thinking that subsequently ensues. Seeds are smaller units of content, designed to allow thoughts to go in all directions (see fig 1). [5] talks of finding 'as small a seed of content stimulus as possible that would ensure that some relevant creative work could be undertaken, but that the nature of it would be determined by the participant.' Another approach comes from design, where absurdist cultural probes [6] such as dream recorders made space for people studied to bring in their own experience.
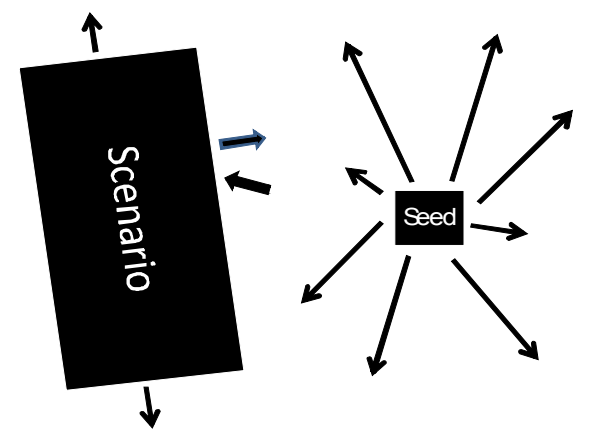

Figure 1. The different thought constellations of scenario and seed content stimuli [4]

Gaver's later work on ambiguity acknowledges the many layers of meaning that technologies carry, but works more analogously with scenarios in that the products also already have definition as something, even if what that is is not clear. Bowen's work [7] on critical design bridges this gap by presenting generic objects that hint at functionality but have none.

\section{THE DISCUSSION}

In what ways might we elicit an audience reaction to the general rather than the specific? How might we capture user concerns or enchantments at an early stage in design: before a working model is available, but in such a way that we can discuss user experience? These are key issues, especially when dealing with nascent technologies, empty social spaces, or future-related material, when we cannot predict form and content. We need ways of working unaccompanied by embedded values, assumed behaviours and implicit meanings, particularly when crossing cultural boundaries where values as well as beliefs may differ.

\section{THE PANELLISTS}

\subsection{Briggs}

Pam Briggs and Linda Little have been developing principles for filmed scenarios that can effectively communicate futuristic technologies to a wide audience (eg [8]). However Briggs will be showing a film from a joint project with Patrick Olivier from Newcastle University's Culture Lab. The film describes a 'biometric daemon': a futuristic biometric pet, based upon the literary work of Philip Pullman, that serves as an authentication device. The concept is explained in detail in [9]: the focus in this panel is on the principles underpinning the film rather than on the device concept. Specifically, the film is designed to be explicitly non-committal about the form of the biometric daemon and yet offers an engaging scene, rich in comedy, that allows the user to speculate as to just what kind of a device the daemon may be.

\subsection{Light (chair)}

Ann Light will be showing material devised as part of the "Democratising Technology" Designing for the $21^{\text {st }}$ Century project, in which a performance artist, cognitive scientist, interaction design researcher and media arts strategist collaborated to create methods for engaging those excluded from digital design decisions and give them the will and the confidence to consider the forms of social relations that they would like ubiquitous digital networks to enable [5]. Working with material offered by participants to explore their interests and priorities, the team avoided suggesting what the future might look and feel like. The resulting workshop method is available on a DVD and here: http://www.thenotquiteyet.net.

\subsection{Martin}

Karen Martin was co-organiser, with Arianna Bassoli and Johanna Brewer, of a series of workshops on in-between-ness, in which researchers from industry and academia, architects, artists and social and computer scientists came together to explore the transitory nature of in-between spaces. These workshops served a dual purpose as an exploration of the topic of in-between-ness and of the nature of interdisciplinary collaboration [10]. Through observation, discussion and design activities the workshops offered participants the opportunity for immersive experience of, and reflection on, the workshop topic. From this a deeper understanding of the subject emerged organically as the workshop progressed. The workshops are documented on www.inbetweeness.org/

\section{THE SCHEDULE}

We anticipate a section of show-and-tell from each panellist before a more general discussion of the ideas. And we will set a brief experiential exercise for the audience in keeping with the theme of the panel before opening the conversation to the floor.

\section{ACKNOWLEDGMENTS}

We thank the AHRC, EPSRC and ACE for their support of "Democratising Technology" and all our co-designers.

\section{REFERENCES}

[1] Little, L., Briggs, P. and Coventry, L. (2004). Videotaped Activity Scenarios and the Elicitation of Social Rules for Public Interactions. In: Proceedings of HCI 2004.

[2] Light, A. (2006) Adding Method to Meaning: a technique for exploring peoples' experience with digital products. Behaviour \& Information Technology, 25 (2), 175-187

[3] Light, A., Blythe, M and Reed, D. (2008) Defamiliarising Design, Design Principles and Practices 1(4) 63-72

[4] Light, A., Healey, P.G.T. and Simpson, G. (2006) Designing the Not Quite Yet. Workshop extended abstract. In: Proceedings of HCI 2006 vol 2

[5] Light, A., Weaver, L., Healey, P.G.T. and Simpson, G. (2008) Adventures in the Not Quite Yet. In: Proceedings of DRS 2008

[6] Gaver, W.W., Boucher, A., Pennington, S. and Walker, B. (2004) Cultural probes and the value of uncertainty. Interactions, 11( 5) 
[7] Bowen, S. J. (2007). Crazy Ideas or Creative Probes?: Presenting Critical Artefacts to Stakeholders to Develop Innovative Product Ideas. In: Proceedings of EAD07.

[8] Little, L., Storer, T., Briggs, P. and Duncan, I. (2008). Evoting in an ubicomp world: Trust, privacy, and social implications. Soc. Science Computer Review, 26(1):44-59.
[9] Briggs, P. and Olivier, P. L. (2008). Biometric Daemons: Authentication by electronic pets. Proceedings of $\mathrm{CHI}$ '08 extended abstracts 2423-2432, ACM Press.

[10] Bassoli, A., Brewer, J. and Martin, K. (2007) In-between Theory and Practice: Dialogues in Design Research. Proceedings of CHI '07, extended abstracts, ACM Press 